\title{
PELAKSANAAN K3 DI RUANG PENYIMPANAN REKAM MEDIS RSU BINA SEHAT
}

\author{
Riski Triyani ${ }^{*}{ }^{*}$, Leni Herfiyanti ${ }^{2}$ \\ Program Studi Rekam Medis Informasi Kesehatan, Politeknik Piksi Ganesha, Indonesia \\ piksi.riskitriyani.18303171@gmail.com ${ }^{1 *}$, leniherfiyanti@gmail.com²
}

Received: 17-07-2021

Revised : 16-09-2021

Accepted: 24-09-2021

\begin{abstract}
Abstrak
Latar Belakang: Keselamatan menjadi kebutuhan bagi setiap mahluk hidup, secara tidak sadar mereka telah mengenal aspek keselamatan itu sendiri untuk mengantisipasi berbagai ancaman bahaya disekitar mereka. Sejalan dengan perkembangan zaman potensi bahaya yang dihadapi akan sangat beragam termasuk bahaya oleh manusia itu sendiri. Mengingat bahwa seluruh kegiatan rekam medis diselenggarakan oleh sumber daya manusia pencarian berkas rekam medis yang dilakukan oleh petugas harus cepat dan tepat bisa menimbulkan kecelakaan jika tidak berhati-hari serta kondisi berkas yang sudah rusak dan berdebu dapat menimbulkan gangguan kesehatan sehingga harus mendapatkan perhatian serius mengenai pelaksanaan K3 di ruang penyimpanan rekam medis RSU Bina Sehat.
\end{abstract} Tujuan: Penelitian ini bertujuan untuk mengetahui K3 di Ruang Penyimpanan Rekam Medis RSU Bina Sehat.

Metode: Metode yang digunakan dalam penelitian ini adalah kualitatif deskriptif dan data primer diperoleh dengan triangulasi. Teknik pengumpulan data yaitu observasi serta wawancara untuk mengetahui permasalahan yang sedang diteliti. Objek penelitian adalah 3 orang petugas penyimpanan rekam medis. Analisis data yang digunakan peneliti terdiri dari data reduction, data display, dan conclusion.

Hasil: Hasil penelitian menunjukan bahwa belum ada prosedur tetap, kurangnya kesadaran petugas mengenai K3, ruang gerak untuk bekerja sempit, alat pelindung diri kurang. Kesimpulan dari penelitian ini adalah pelaksanaan K3 belum baik.

Kesimpulan: Kesimpulan dari penelitian ini adalah pelaksanaan keselamatan dan Kesehatan kerja di ruang penyimpanan rekam medis RSU Bina Sehat dikatakan belum baik karena masih ditemukan beberapa permasalahan yang dapat menimbulkan kecelakaan pada petugas rekam medis sehingga mempengaruhi pada kinerja petugas.

Kata kunci: pelaksanaan keselamatan dan kesehatan kerja; ruang penyimpanan; rekam medis. 
Background: Safety is a necessity for every living creature. Unconsciously they already know the aspect of safety itself to anticipate various threats of danger around them. In line with the times, the potential dangers faced will be very diverse, including the dangers caused by humans themselves. Given that human resources carry out all medical record activities, the search for medical record files carried out by officers must be fast and precise, it can cause accidents if not careful, and the condition of files that are damaged and dusty can cause health problems, so serious attention must be paid to the implementation $K 3$ in the medical record storage room of the Bina Sehat Hospital. Objective: This research aimed to know about review of health and job safety in the medical record storage room at "RSU Bina Sehat".

Methods: These methods used descriptive qualitative and the primary source of data is obtained by triangulation. Techniques of data collection used observation and interviews to find out the problem being researched. The object of this research is three people, medical record officers.

Results: The result showed that it was a lack of fixed procedures, it was a lack of employee awareness of occupational health and safety, space to work was very narrow, it was lack protective equipment The conclusion of this research is the implementation of Occupational Health and Safety is not too good.

Conclusion: This study concludes that the implementation of occupational safety and health in the medical record storage room of Bina Sehat Hospital is said to be not good because there are still some problems that can cause accidents to medical record officers. It affects the performance of the officers.

Keywords: implementation of health and job safety; storage space; medical record.

*Coresponden Author : Riski Triyani

*Email: piksi.riskitriyani.18303171@gmail.com

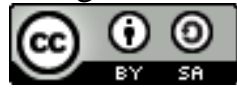

\section{PENDAHULUAN}

Keselamatan menjadi kebutuhan bagi setiap mahluk hidup, secara tidak sadar mereka telah mengenal aspek keselamatan itu sendiri untuk mengantisipasi berbagai ancaman bahaya di sekitar mereka. Sejalan dengan perkembangan zaman potensi bahaya yang dihadapi akan sangat beragam termasuk bahaya oleh manusia itu sendiri (Afianto, n.d.).

Keselamatan dan Kesehatan Kerja di fasilitas pelayanan kesehatan yang selanjutnya disebut K3 di fasyankes adalah segala kegiatan untuk menjamin dan melindungi sumber daya manusia fasilitas pelayanan kesehatan, pasien, pendamping pasien, pengunjung, maupun masyarakat di sekitar lingkungan fasilitas pelayanan kesehatan agar sehat, selamat, dan bebas dari gangguan kesehatan dan pengaruh buruk yang 
diakibatkan dari pekerjaan, lingkungan, dan aktivitas kerja (Indonesia, 2018). Maka seluruh sarana pelayanan kesehatan harus menjamin kenyamanan karyawan saat bekerja untuk mengurangi kecelakaan dan penyakit akibat bekerja, maka dari itu perlu diperhatikan adanya Alat Pelindung Diri (APD) untuk setiap petugas rekam medis, terutama petugas di ruang penyimpanan rekam medis sehingga dapat meningkatkan produktivitas kerja petugas (Sahputri, 2020).

Mengingat bahwa seluruh kegiatan rekam medis diselenggarakan oleh sumber daya manusia pencarian rekam medis yang dilakukan oleh petugas harus cepat dan tepat, bisa menimbulkan kecelakaan jika tidak berhati-hati serta kondisi yang sudah rusak dan berdebu dapat menimbulkan gangguan kesehatan (Kurniawan, 2014), sehingga harus mendapatkan perhatian serius mengenai pelaksanaan keselamatan dan kesehatan kerja bagian penyimpanan rekam medis di RSU Bina Sehat Bandung.

Pada penelitian sebelumnya ditemukan bahwa petugas yang mengalami kecelakaan kerja lebih banyak sedangkan pada penelitian ini kecelakaan kerja terhadap petugas di ruang penyimpanan rekam medis RSU Bina Sehat lebih sedikit. Suatu upaya untuk mencegah permasalahan ini yaitu dengan petugas yang harus saling mengingatkan untuk berhati-hati saat bekerja dan kesadaran petugas mengenai keselamatan dan kesehatan kerja harus lebih diutamakan.

Pentingnya penelitian ini adalah sebagai kajian bagi para petugas dan pihak pengurus keselamatan dan kesehatan kerja (K3) di ruang penyimpanan rekam medis RSU Bina Sehat atau pihak lain yang akan meneliti masalah ini lebih lanjut. Adapun tujuan dari penelitian yang dilakukan yaitu untuk mengetahui pelaksanaan keselamatan dan Kesehatan kerja (K3) di ruang penyimpanan rekam medis RSU Bina Sehat dan permasalahan apa saja yang berkaitan dengan pelaksanaan keselamatan dan Kesehatan kerja di ruang penyimpanan rekam medis RSU Bina Sehat.

\section{METODE PENELITIAN}

Penelitian ini menggunakan penelitian kualitatif (Andoyo, 2019) dimana penelitian adalah sebagai instrumen penelitian. Teknik pengumpulan data dilakukan secara trianggulasi atau gabungan (Bening Azhilmi, 2018) data yang dihasilkan bersifat deskriptif dan tinjauan yang dilakukan secara indukatif (AZIZ, 2017). Hasil penelitian lebih menekankan makna dan generalisasi. Lokasi penelitian yaitu di RSU Bina Sehat beralamat di J1. Raya Dayeuhkolot No.325, Citeureup, Kec. Dayeuhkolot, Bandung, Jawa Barat 40257. Penelitian dilakukan selama 2 bulan yaitu pada bulan April hingga Mei 2021.

Dalam penelitian ini yang menjadi objek penelitian adalah petugas penyimpanan rekam medis di RSU Bina Sehat Bandung berjumlah 3 orang. Data primer didapatkan dari wawancara dan observasi. Sedangkan data sekunder didapat dari berbagai platform yang berhubungan dengan judul untuk mengetahui permasalahan yang sedang diteliti sehingga mempermudah untuk menghasilkan data. Analisis data yang digunakan peneliti terdiri dari data reduction, data display, dan conclusion.

\section{HASIL DAN PEMBAHASAN}

\section{A. Hasil Penelitian}

\section{Pelaksanaan K3 di Ruang penyimpanan Rekam Medis RSU Bina Sehat}

Pelaksanaan Keselamatan dan Keseahatan Kerja di bagian penyimpanan rekam medis RSU Bina Sehat, berdasarkan hasil penelitian penulis selama 2 bulan beberapa aspek 
Keselamatan dan Kesehatan kerja (K3) rekam medis bagian penyimpanan dikatakan belum terlalu baik seperti perancangan tata ruang. Kurang luasnya ruang penyimpanan rekam medis yang telah dipenuhi oleh rak-rak rekam medis yang didukung oleh udara pada ruangan penyimpanan menjadi pengap, panas, dan berdebu (Susanto et al., 2019) Serta tidak terpenuhinya beberapa syarat keselamatan dan kesehatan kerja dibagian ruang penyimpanan rekam medis diantaranya, kurangnya penerangan dalam ruangan penyimpanan rekam medis, tidak tersedianya kotak P3K, tangga hanya tersedia 1 buah, tidak terdapat sarung tangan khusus bagi petugas, ketidaktahuan/kurangnya tingkat kesadaran petugas terhadap keselamatan dan kesehatan kerja (Arsyah et al., 2021).

Keselamatan dan Kesehatan Kerja (K3) adalah perlindungan pada tenaga kerja yang memasuki tempat kerja dari bahaya sekitar. Oleh karena itu, ruang penyimpanan rekam medis harus dijaga suhu dan kelembabannya serta mampu melaksanakan dan menciptakan tempat kerja aman, sehat, terbebas dari gangguan kesehatan sehingga dapat meningkatkan produktivitas kerja.

\section{Pencegahan Tingkat Kecelakaan Kerja di Ruang Penyimpanan Rekam Medis RSU Bina Sehat}

Pencegahan Tingkat Kecelakaan Kerja di Bagian Penyimpanan Rekam Medis RSU Bina Sehat berdasarkan hasil penelitian penulis selama 2 bulan dari bulan April sampai dengan bulai Mei 2021 dapat dikatakan belum baik sebagai berikut:

1. Belum adanya prosedur tetap mengenai keselamatan dan kesehatan kerja serta alat yang baik untuk kenyamanan bekerja.

2. Kurangnya kesadaran petugas tentang pentingnya keselamatan dan kesehatan kerja dalam hal keamanan, kebersihan dan kenyamanan.

3. Tata ruang sangat sempit dan dipenuhi oleh rak-rak penyimpanan rekam medis sehingga membatasi gerak bekerja.

4. Penyediaan alat pelindung diri kurang.

Sekecil apapun kecelakaan yang terjadi akan berakibat penurunan efisiensi (Puji, 2019) tugas utama untuk manajemen dalam menyelenggarakan keselamatan dan kesehatan kerja dan pemberian pertolongan pertama pada seluruh petugas, agar produktivitas kerja petugas tidak terganggu (Kampar, n.d.).

Adapun yang menjadi tanggung jawab manajemen dalam mencegah terjadinya kecelakaan kerja adalah membimbing untuk mencegah kecelakaan dan meyakinkan petugas tentang pentingnya keselamatan dan kesehatan kerja petugas dalam kondisi yang aman untuk meningkatkan produktivitas kerja petugas agar senantiasa lebih baik guna mencapai tujuan secara efektif (Jati Kusuma \& Darmastuti, 2011).

Selain itu petugas diberi arahan dan pelatihan sehingga dapat bekerja sesuai peraturan mengenai K3, pihak Rumah Sakit terutama bagian Rekam Medis menginformasikan hal baru seputar K3 di ruang penyimpanan, petugas melakukan retensi bertahap sehingga efektif, petugas menggunakan APD untuk mencegah kecelakaan kerja di ruang penyimpanan rekam medis.

\section{Tinjauan Pelaksanaan K3 di Ruang penyimpanan Rekam Medis RSU Bina Sehat.}

Berikut penerapan $\mathrm{K} 3$ di ruang penyimpanan rekam medis dapat digambarkan seperti :

1. Kebersihan

Untuk menjaga kesehatan ruangan hendaknya selalu dalam keadaan bersih, bahan buangan dan sisa diupayakan disingkirkan di luar jam kerja untuk menghindari resiko kesehatan (Cahyati, 2014).

2. Air minum dan kesehatan

Air minum yang baik dan bersih harus disediakan di dekat tempat kerja. 


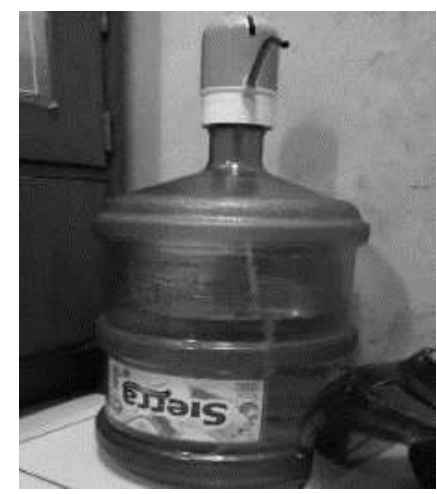

Gambar 1. Galon Air Minum (Ruang Penyimpanan RM RSU Bina Sehat,2021)

3. Kerapihan ruangan

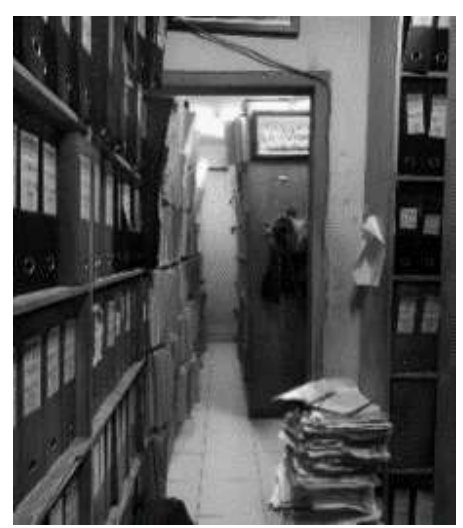

Gambar 2.1

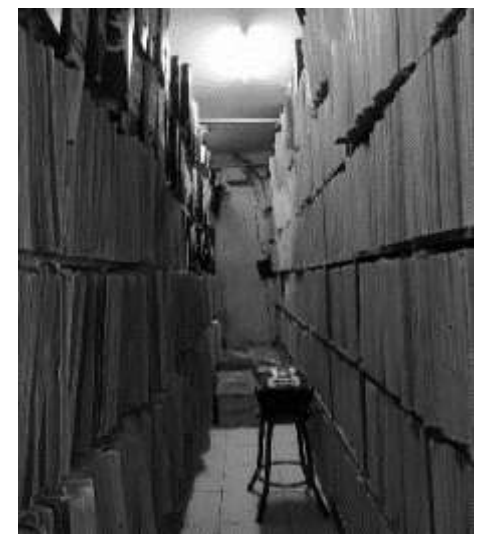

Gambar 2.2 Tata Ruang penyimpanan rekam medis (Ruang Penyimpanan RM RSU Bina Sehat Bandung)

Kerapihan ruang kerja tidak tertata sehingga tidak aman dalam mencegah kecelakaan dan dapat mengganggu produktivitas pekerja. (Suharti \& Mudayana, 2020)

4. Ventilasi udara, pemanas, pendingin 


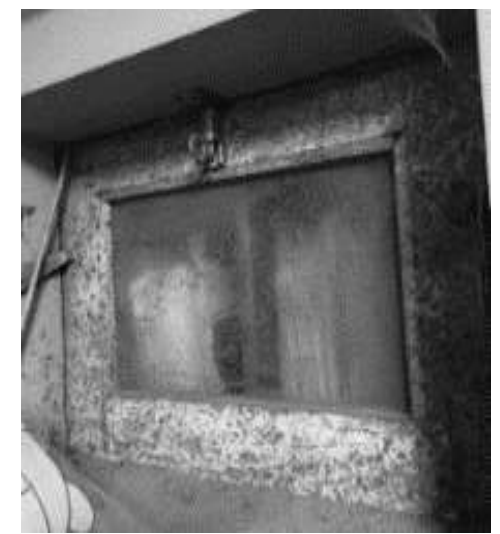

Gambar 3.1 Ventilasi Udara

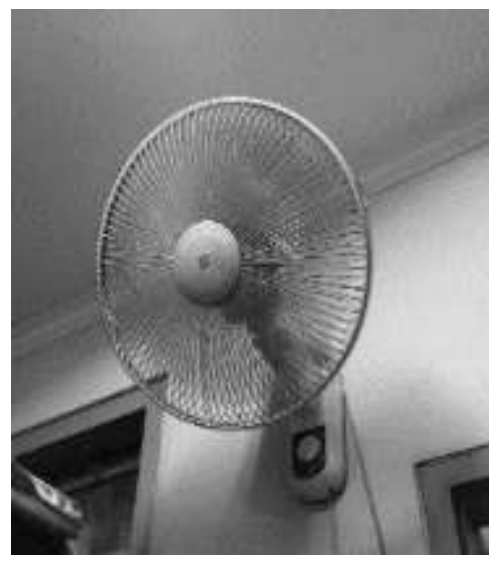

Gambar 3.2 Kipas Angin/Pendingin

(Ruang Penyimpanan RM RSU Bina Sehat Bandung)

Ventilasi udara yang berfungsi sebagai pengontrol udara segar menggantikan udara kotor yang tertutup oleh rak penyimpanan sehingga ruangan menjadi panas, pengap dan berdebu (Aep Saepudin Catur et al., 2017).

5. Tempat kerja, ruang kerja, tempat duduk

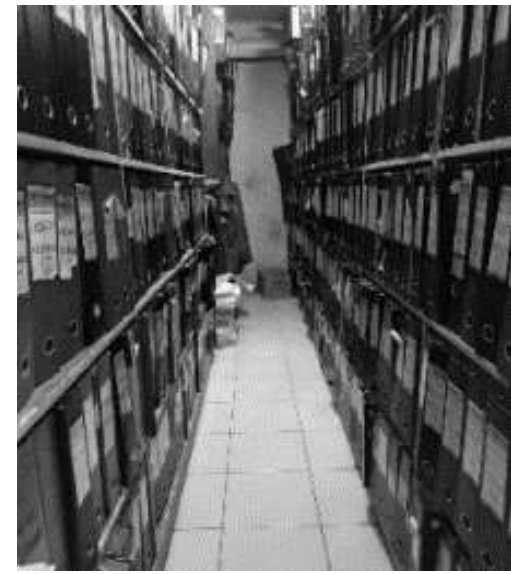

Gambar 4. Rak terbuka

(Ruang Penyimpanan RM RSU Bina Sehat Bandung) 
Tempat kerja yang sempit tidak nyaman dan aman sehingga tidak ada tempat duduk yang sesuai untuk petugas beristirahat.

6. Pencegahan kecelakaan

Pencegahan kecelakaan harus dilakukan entah itu sebab teknis maupun yang disebabkan oleh manusia itu sendiri.

7. Pencegahan kebakaran

Untuk semua yang bersangkutan perlu dilaksanakan peraturan tersebut, seperti larangan merokok di tempat yang mudah timbul kebakaran.

8. Gizi

Dengan gizi yang baik bagi petugas akan mampu menghasilkan energi yang sehat serta daya tahan tubuh yang kuat.

9. Pencahayaan/Penerangan

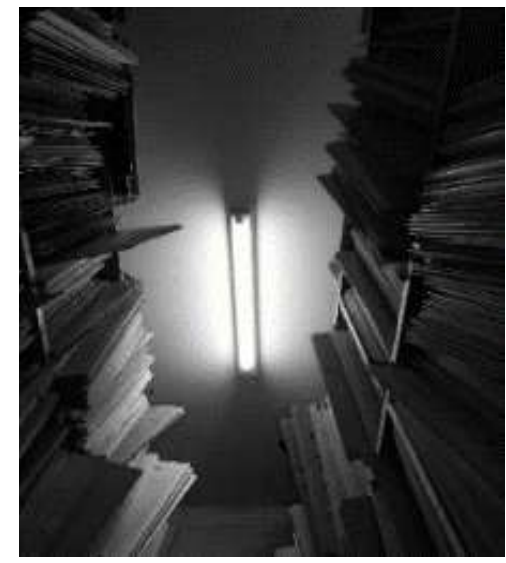

Gambar 5. Pencahayaan

(Ruang Penyimpanan RM RSU Bina Sehat Bandung)

Pencahayaan di ruang penyimpanan rekam medis belum memenuhi aspek K3 dengan tujuan pekerja dapat bekerja secara jelas, cepat, nyaman dan aman.

Berikut peralatan penunjang yang digunakan di ruang penyimpanan rekam medis.

a. Tangga

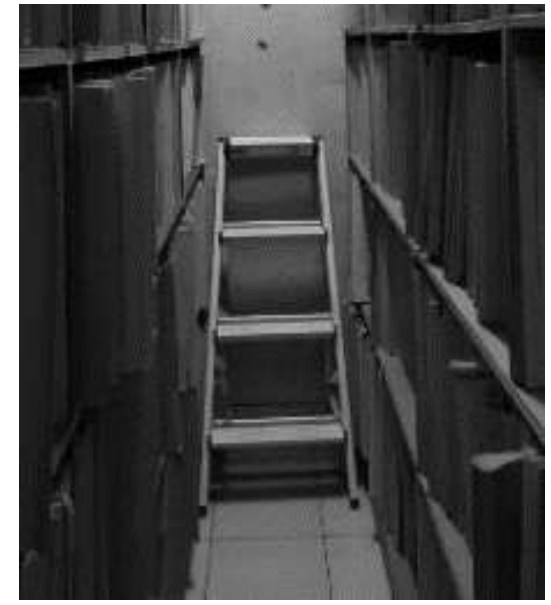

Gambar 6. Tangga

(Ruang Penyimpanan RM RSU Bina Sehat Bandung) 
Digunakan untuk mengambil rekam medis yang berada di rak atas, tetapi petugas menggunakannya sebagai alas untuk duduk serta tangga yang tersedia pada ruang penyimpanan rekam medis hanya ada 1 buah.

b. Jalur Evakuasi Bencana

Di bagian rekam medis tidak mempunyai jalur evakuasi tersendiri sehingga petugas penyimpanan dan pendaftaran bersatu menuju parkiran yang menjadi titik kumpul jika terjadi bahaya.

Adapula Resiko Kecelakaan di Bagian Penyimpanan Rekam Medis RSU Bina Sehat :

1. Kejadian bersifat kebetulan.

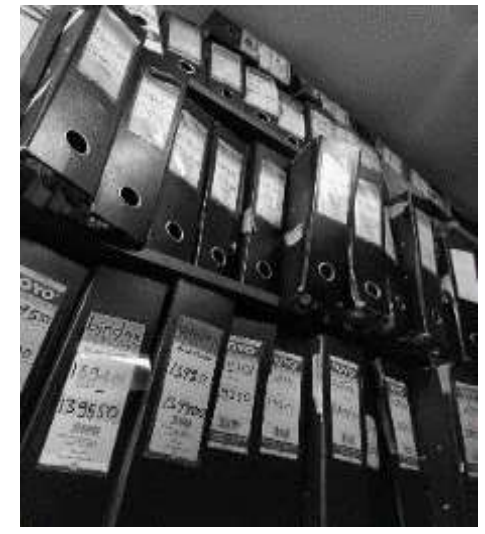

Gambar 7.1 Rak terbuka

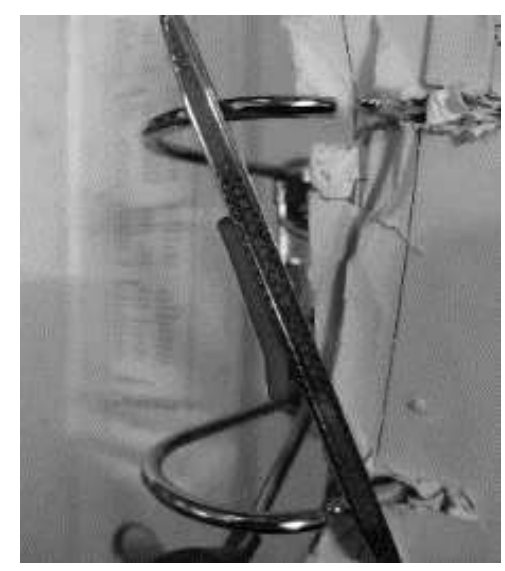

Gambar 7.2 Bindex

(Ruang Penyimpanan RM RSU Bina Sehat Bandung)

Berdasarkan hasil observasi yang dilakukan penulis kecelakaan yang terjadi di ruang penyimpanan rekam medis akibat tidak memakai alat pelindung diri misalnya petugas tidak memakai sarung tangan saat pengambilan dan penyimpanan rekam medis sehingga terluka karena tajamnya amplop rekam medis dan sempitnya jarak pengambilan rekam medis.

2. Kondisi tidak aman

Dari hasil observasi dan wawancara langsung yang dapat menimbulkan kecelakaan kerja yaitu peralatan pelindung yang tidak memadai, peralatan yang digunakan petugas rusak sehingga petugas bekerja menggunakan alat seadanya. Ruangan penyimpanan rekam medis terlalu penuh dan sumpek, tidak adanya tempat istirahat untuk petugas dan penerangan kurang memadai yang mengakibatkan ruangan pengap. 
3. Tindakan-tindakan yang tidak aman

Tindakan-tindakan yang petugas lakukan belum sepenuhnya mereka sadari bahwa dapat menimbulkan kecelakaan. Bekerja dengan kecepatan yang tidak aman karena banyaknya pasien yang berobat yang harus menyesuaikan kecepatan dalam mengangkat rekam medis secara terburu-buru yang akan didistribusi dapat menimbulkan kecelakaan kerja dan pikiran kacau dapat mempengaruhi produktivitas kerja petugas.

Berdasarkan hasil tersebut maka pelaksanaan K3 di ruang penyimpanan rekam medis RSU Bina Sehat tidak efektif seperti kurang luasnya ruangan penyimpanan yang mempengaruhi pada kerapihan serta kenyamanan bekerja, ventilasi udara kurang baik sehingga ruangan menjadi panas dan pengap, tempat kerja yang sempit tidak bisa menyediakan tempat duduk bagi petugas dan pencahayaan/penerangan belum memadai di ruangan penyimpanan rekam medis RSU Bina Sehat Bandung.

Tabel 1. Data hasil penelitian kecelakaan kerja terhadap 3 orang petugas bagian penyimpanan rekam medis

\begin{tabular}{|c|c|c|c|c|c|}
\hline \multirow[b]{2}{*}{$\mathbf{o}$} & \multirow[t]{2}{*}{ Nama Petugas } & \multicolumn{4}{|c|}{ Jenis Kecelakaan } \\
\hline & & $\mathbf{A}$ & B & C & D \\
\hline 1. & Suhana & $\sqrt{ }$ & & $\sqrt{ }$ & \\
\hline 2. & Utuy Mulyawan & & $\sqrt{ }$ & & $\sqrt{ }$ \\
\hline 3. & Fitri R Wijaya & $\sqrt{ }$ & $\sqrt{ }$ & & \\
\hline
\end{tabular}

Keterangan tabel :

A : Cedera Lecet Jari

B : Cedera Otot Tangan

C: Cedera Otot Pinggang

D : Cedera Otot Kaki

Berdasarkan data yang disajikan pada tabel 1 menunjukan bahwa, untuk kejadian cedera lecet jari sebanyak 2 kali dan kejadian cedera otot tangan sebanyak 2 kali. Hal ini disebabkan karena sempitnya jarak antara sekat dan tajamnya amplop rekam medis.

Potensi bahaya lainnya di ruang penyimpanan rekam medis yang mempengaruhi situasi dan kondisi yaitu kecelakaan yang berhubungan dengan listrik dan sumber-sumber cidera lainnya. Semua potensi bahaya tersebut jelas mengancam jiwa bagi petugas maupun pasien dan pengunjung rumah sakit.

\section{KESIMPULAN}

Pelaksanaan Keselamatan dan Kesehatan Kerja (K3) di ruang penyimpanan Rekam Medis RSU Bina Sehat Bandung dikatakan minim dan belum mendapatkan perhatian mengenai pelaksaan Keselamatan dan Kesehatan Kerja rekam medis, termasuk di bagian penyimpanan rekam medis yang dinilai belum terlalu baik. Masih ada permasalahan yang ditemukan seperti, belum adanya prosedur tetap kurangnya kesadaran petugas, ruang gerak bekerja sangat sempit, dan alat pelindung diri (APD) kurang.

Upaya yang telah dilakukan untuk menangani permasalahan ini adalah dengan mengusulkan prosedur tetap, petugas rekam medis saling mengingatkan untuk berhati-hati dalam melaksanakan pekerjaannya, dengan jumlah pasien yang bertambah maka semakin banyak berkas di ruang penyimpanan sehingga rumah sakit melakukan retensi agar ruang 
gerak menjadi efektif, menyediakan pertolongan pertama yaitu kotak P3K agar produktivitas petugas tidak terhambat.

\section{BIBLIOGRAFI}

Aep Saepudin Catur, S. T., Yahya, M., \& Fauzi, D. S. (2017). Revitalisasi Pasokan Udara Segar Sistem Ventilasi (Kla12) Reaktor Serba Guna Ga Siwabessy. Reaktor: Buletin Pengelolaan Reaktor Nuklir, 13(2), 66-80.

Afianto, S. N. (n.d.). Hubungan Antara Pengetahuan Dan Sikap Dengan Tindakan Pekerja Dalam Bekerja Sesuai Safety Sign Boards Yang Terpasang (Studi di Sub Divisi Wood Working 1 PT. Kutai Timber Indonesia Probolinggo).

Andoyo, B. (2019). Pengaruh Current Ratio (Cr), Earning Per Share (Eps), Dan Ukuran Perusahaan (Size) Terhadap Harga Saham Pada Perusahaan Indeks Lq45 Yang Terdaftar Di Bursa Efek Indonesia Tahun 2013-2017. Universitas Buddhi Dharma.

Arsyah, F. A., Hidayah, S. N., \& Herfiyanti, L. (2021). Keamanan, Kesehatan dan Keselamatan Kerja Petugas Penyimpanan di Rumah Sakit X Kota Cimahi. Cerdika: Jurnal Ilmiah Indonesia, 1(7), 808-8014.

AZIZ, N. F. (2017). Peranan Orang Tua Dalam Mengatasi Perilaku Menyimpang Dikalangan Remaja (Studi Deskriptif kelas XI di Sekolah Menengah Kejuruan Pasundan 3 Bandung). FKIP Unpas.

Bening Azhilmi, F. (2018). Strategi Komunikasi Pemasaran Melalui Instagram Untuk Meningkatkan Penjualan Depot Sataichan Surabaya. Universitas Ciputra Surabaya.

CAHYATI, N. (2014). Peranan Kesehatan dan Keselamatan Kerja (K3) dalam Memperlancar Aktivitas Kerja Karyawan pada PT Sinar Sosro Pabrik Palembang. Politeknik Negeri Sriwijaya.

Indonesia, P. M. K. R. (2018). Keselamatan dan Kesehatan Kerja Lingkungan Kerja. Jakarta.

Jati Kusuma, I., \& Darmastuti, I. (2011). Pelaksanaan program keselamatan dan kesehatan kerja karyawan PT. Bitratex Industries Semarang. Universitas Diponegoro.

KAMPAR, A. (n.d.). Pengaruh Keselamatan Dan Kesehatan Kerja Terhadap Kinerja Karyawan Pada CV. Suci Karya.

Kurniawan, A. (2014). Pelaksanaan Program Keselamatan dan Kesehatan Kerja (K3) Karyawan PT. Nuansacipta Coal Investment (NCI) di Kelurahan Bantuas Kecamatan Palaran Kota Samarinda.

PUJI, K. (2019). Identifikasi Penyebab Terjadinya Kecelakaan Kerja Pada Anak Buah Kapal Bagian Mesin Di Kamar Mesin Kmp. Portlink. Politeknik Ilmu Pelayaran Semarang.

Sahputri, A. H. (2020). K3 Untuk Peningkatan Keselamatan Diri Perawat.

Suharti, S., \& Mudayana, A. A. (2020). Penerapan Program Safety Behavior Audit Dalam Upaya Pencegahan Kecelakaan Kerja Pada Kontraktor Di Pt Sarihusada Generasi Mahardika Plant Yogyakarta. Jurnal Kesehatan Masyarakat, 13(2).

Susanto, E., Pujiastuti, R. S. E., \& Cahyaningsih, R. D. (2019). Keselamatan dan Kesehatan Kerja Pada Penyimpanan Rekam Medis di Instalasi Rekam Medis. Jurnal Rekam Medis Dan Informasi Kesehatan, 2(1), 26-33.

(C) 2021 by the authors. Submitted for possible open access publication under the terms and conditions of the Creative Commons Attribution (CC BY SA)

license (https://creativecommons.org/licenses/by-sa/4.0/). 